\title{
Evidence for local dendritic cell activation in pulmonary sarcoidosis
}

\author{
Bregje Ten Berge ${ }^{1}$, Alex KleinJan ${ }^{1}$, Femke Muskens ${ }^{1}$, Hamida Hammad ${ }^{2}$, Henk C Hoogsteden ${ }^{1}$, Rudi W Hendriks ${ }^{1}$, \\ Bart N Lambrecht ${ }^{1,2+}$ and Bernt Van den Blink ${ }^{1 *+}$
}

\begin{abstract}
Background: Sarcoidosis is a granulomatous disease characterized by a seemingly exaggerated immune response against a difficult to discern antigen. Dendritic cells (DCs) are pivotal antigen presenting cells thought to play an important role in the pathogenesis. Paradoxically, decreased DC immune reactivity was reported in blood samples from pulmonary sarcoidosis patients. However, functional data on lung DCs in sarcoidosis are lacking. We hypothesized that at the site of disease DCs are mature, immunocompetent and involved in granuloma formation.

Methods: We analyzed myeloid DCs (mDCs) and plasmacytoid DCs (pDCs) in broncho-alveolar lavage (BAL) and blood from newly diagnosed, untreated pulmonary sarcoidosis patients and healthy controls using 9-color flowcytometry. DCs, isolated from BAL using flowcytometric sorting (mDCs) or cultured from monocytes (mo-DCs), were functionally assessed in a mixed leukocyte reaction with naïve allogeneic CD4+ T cells. Using Immunohistochemistry, location and activation status of CD11 $c^{+} D C s$ was assessed in mucosal airway biopsies.

Results: mDCs in BAL, but not in blood, from sarcoidosis patients were increased in number when compared with $\mathrm{mDCs}$ from healthy controls. mDCs purified from BAL of sarcoidosis patients induced T cell proliferation and differentiation and did not show diminished immune reactivity. Mo-DCs from patients induced increased TNF $\alpha$ release in co-cultures with naïve allogeneic $\mathrm{CD}^{+} \mathrm{T}$ cells. Finally, immunohistochemical analyses revealed increased numbers of mature $C D 86^{+}$DCs in granuloma-containing airway mucosal biopsies from sarcoidosis patients.
\end{abstract}

Conclusion: Taken together, these finding implicate increased local DC activation in granuloma formation or maintenance in pulmonary sarcoidosis.

Keywords: Sarcoidosis, Dendritic cells, Bronchoalveolar lavage, Granuloma, TNFa

\section{Background}

Sarcoidosis is a systemic disease characterized by the presence of noncaseating granulomas in involved organs, affecting the lung in more than $90 \%$ of patients $[1,2]$. The granulomatous reaction occurs in the absence of a clearly defined immunological target. However, a reaction to an unidentified antigen is suspected [3]. An antigen-driven pathogenesis is supported by disease-associated polymorphisms in genes encoding antigen recognizing or antigen presenting molecules such as Toll-like receptors and MHC class II [4]. Epidemiological and experimental

\footnotetext{
* Correspondence: b.vandenblink@erasmusmc.nl

+ Contributed equally

'Department of Pulmonary Medicine, Erasmus MC, Dr. Molewaterplein 50,

3015, GE Rotterdam, The Netherlands Full list of author information is available at the end of the article
}

data are suggestive of airborne or infectious antigens, in particular mycobacterial peptides, but attempts to link sarcoidosis to a causative pathogen are difficult and remain controversial [5-7]. Increased numbers of $\mathrm{CD}_{4}^{+}$ $\mathrm{T}$ cells in the broncho-alveolar lavage (BAL) fluid are a further hallmark of disease [3,4]. Increased proportions of oligoclonal $\mathrm{CD}_{4}^{+} \mathrm{T}$ cells were found in the BAL from patients with sarcoidosis, consistent with a MHCrestricted antigen-driven process $[8,9]$. Both granuloma formation and $\mathrm{T}$ cell alveolitis have been characterized as Th-1 responses $[3,4,10-12]$. These data have led to the hypothesis that sarcoidosis emerges from an exaggerated Th1 immune response upon presentation of an unidentified antigen by an antigen presenting cell (APC).

Past studies on APCs involved in pulmonary sarcoidosis focused on alveolar macrophages $[8,9,13]$. However,

\section{() Biomed Central}


in recent years it has become clear that dendritic cells (DCs) are the key APCs in the lung, responsible for presentation of antigen in draining lymph nodes, inducing $\mathrm{T}$ cell activation and proliferation [14,15]. Models of granulomatous disease in response to mycobacterial antigens showed that DCs contribute to granuloma formation [16-18]. We recently found that pulmonary granuloma formation is dependent on the presence of DCs and DC-induced T cell proliferation in draining lymph nodes [19]. These data suggest that DCs are pivotal mediators in the pathogenesis of sarcoidosis. Indeed, DCs were observed in skin, lymph node and lung lesions from sarcoidosis patients $[14,20]$. Lymph node granulomas contained many mature DCs expressing the lysosome-associated membrane glycoprotein DC-LAMP, which is induced upon DC maturation [21]. These DCLAMP $^{+}$DC were typically located in the lymphocyte layer of granulomas and adjacent to $\mathrm{CD}^{+} \mathrm{T}$ cells, suggesting functional DC-T cell interaction [21]. In muscular sarcoidosis, recruitment of $\mathrm{mDCs}$ and upregulation of the CD40/CD40L system in affected muscles suggested that $\mathrm{mDCs}$ would be involved in granulomatous inflammation through antigen presentation in a Th1 immune milieu [22]. However, there is debate about the number and function of DCs in pulmonary sarcoidosis: numbers of myeloid DCs (mDCs) and plasmacytoid DCs (pDCs) in peripheral blood of pulmonary sarcoidosis patients were reported to be either normal or reduced $[21,23]$. On the other hand, proportions of pDC and $\mathrm{mDC}$ in the BAL of sarcoidosis patients were reported to be similar and increased, respectively, when compared with healthy controls [24]. Also, decreased proportions of BAL mDCs were found positive for CD83 and CD86, suggesting an immature phenotype of these cells $[24,25]$. Furthermore, peripheral blood $\mathrm{mDCs}$ and in vitro differentiated monocyte-derived DCs (mo-DCs) from sarcoidosis patients demonstrated either a decreased or a normal ability to stimulate $\mathrm{T}$ cells in co-culture experiments $[23,26]$. These data have led to the prevailing opinion that in pulmonary sarcoidosis, DCs are immature and anergic in the lung [25]. Thus, the exaggerated immune response in pulmonary sarcoidosis is paradoxically associated with DCs displaying diminished immunoreactivity. Studies into this area have been hampered by technical difficulties in isolating functionally active DCs with a high degree of purity from the site of active disease. It therefore remained unclear whether pulmonary DCs are functionally different in sarcoidosis.

In this study, we set out to investigate whether local DCs are functionally different in patients with pulmonary sarcoidosis, employing our recently developed cell sorting strategy to isolate functionally active DCs from BAL fluid [27]. We found that at the site of disease, more and mature DCs are present in association with granulomas.
Furthermore, DCs from patients with sarcoidosis display intrinsic properties associated with induction of an exaggerated immune response.

\section{Materials and methods}

\section{Patients and healthy control subjects}

After informed consent, a total of 44 patients with sarcoidosis underwent fibre-optic bronchoscopy. The diagnosis of sarcoidosis was made according to the guidelines of the ATS/ERS/WASOG statement on sarcoidosis [2]. None of the patients were on systemic corticosteroid or immunosuppressive drugs one year previous to or at the time of diagnosis and sampling. Patient characteristics are shown in Table 1. 34 healthy controls (male/female ratio of $11 / 22$, median age 22.5 (19-31), 3 smokers) underwent fibre-optic bronchoscopy with BAL (14 controls) or mucosal biopsies (20 controls, from a previous study). As a further control, BAL from three subjects, all smokers, who underwent bronchoscopy to exclude pulmonary sarcoidosis (a $41 \mathrm{yr}$ old patient with uveitis, a 32 yr old patient with ocular vasculitis and a 50 year old patient with parotic enlargement), and that were found to be without sarcoidosis or signs of pulmonary disease at time of bronchoscopy or during 2 years of follow up, was used. The protocol was approved by the Medical Ethical Committee of the Erasmus MC in Rotterdam. In different experiments, samples from subsets of patients and controls were used due to limits in sample availability. When applicable, key characteristics of patient/control subsets are mentioned with each experiment.

\section{Collection of BAL, peripheral blood cells and mucosal biopsies}

BAL was performed with a flexible fibre-optic bronchoscope (Olympus) placed in the right middle lobe in wedge position. Four aliquots of $50 \mathrm{ml}$ saline were instilled and subsequently gently aspirated. BAL fluid was collected in siliconized bottles to prevent cell adherence and kept at $4{ }^{\circ} \mathrm{C}$. BAL fluid was filtered through a $100 \mu \mathrm{m}$ cell strainer (BD Biosciences) and centrifuged for $7 \mathrm{~min}$ at $450 \mathrm{~g}$ at $4^{\circ} \mathrm{C}$. Supernatants were aliquoted for ELISA. A portion of BAL fluid cells were counted and used directly to assess DC number and phenotype. Remaining BAL cells were frozen in $1 \mathrm{ml}$ RPMI 1640 (Gibco), 10\% FCS, $10 \%$ DMSO in a cryovial using a 5100 Cryo $1^{\circ} \mathrm{C}$ Freezing Container (Nalgene) to $-80^{\circ} \mathrm{C}$ and stored at $-150^{\circ} \mathrm{C}$. Upon thawing, macrophages were depleted before further flowcytometric analysis or sorting, as described previously [27]. Peripheral blood mononuclear cells (PBMCs) were collected as described before and used directly to assess DC number and phenotype or frozen as described above [27]. Mucosal biopsies were frozen in Tissue Tek, O.C.T. compound, (Sakura Finetek Europe) and stored at $-80^{\circ} \mathrm{C}$. 
Table 1 Patient characteristics

\begin{tabular}{ll}
\hline & Patients $(\mathbf{n}=\mathbf{4 4})$ \\
\hline Age, years & $37.5(18-67)$ \\
\hline Sex, male/female & $17 / 27$ \\
\hline Stage, (I/II) & $8 / 36$ \\
\hline Diagnosis based on: & $21 / 23$ \\
\hline \multicolumn{1}{c}{ Biopsy } & 17 \\
\hline \multicolumn{1}{c}{ CD4/8 ratio } & 27 \\
\hline CD4/8 ratio, mean & $4.8(1.2-10)$ \\
\hline Extra-thoracic sarcoidosis (number of subjects) & Eye (12), Skin (10), Joints/Arthralgia (9) \\
\hline Co-morbidities & Cardiovascular, including hypertension (3), \\
(number of subjects) & Diabetes Mellitus (2), Thyroid disease (2) \\
& Sickle-cell disease (1), Psoriasis (1), Migraine (2)
\end{tabular}

Data are presented as median (range), unless otherwise stated.

\section{Flow cytometric analysis and sorting}

PBMCs, BAL cells or cultured DCs were incubated in FACS buffer (PBS supplemented with $0.25 \%$ BSA, $0.5 \mathrm{mM}$ EDTA and $0.05 \%$ NaN3 and stained with the following antibodies: FITC-conjugated anti-CD3 (UCHT1), antiCD14 (61D3), anti-CD56 (MEM188), anti-CD4 PE-Cy5 (RPA-T4), anti-CD123-PE (6H6), anti-FoxP3-APC, all from eBiosciences, FITC-conjugated anti-CD16 (3 G8), anti-CD19 (HIB19) and anti-CD25 (2A3), PE-conjugated or biotinylated anti-CD80 (L307.4), anti-CD86 (2331(FUN1)) or CD45RO (UCHI-1), APC-conjugated anti-CD83 (HB15e) and anti-CD40 (5 C3), anti-CD11c PE-Cy5 (B-ly6) and anti-HLA-DR PE-Cy7 (L243), all from BD Biosciences, as well as anti-CD123-APC (AC145, Miltenyi), antiCXCR3-PE (49801)(R\&D) and anti-DC-LAMP-PE (104. G4) (Immunotech). 1\% heat inactivated human serum was added to prevent non-specific antibody staining. Fixable Aqua Dead Cell Stain kit for 405 nm (Invitrogen, Molecular Probes) was used as a live/dead marker. Cells were measured on a LSRII Flowcytometer (BD Biosciences). pDCs and $\mathrm{mDCs}$ were recognized based on forward and side scatter characteristics and expression of different markers. A FITC-labeled lineage mix, containing antibodies against CD3, CD14, CD16, CD19 and CD56 was used. mDCs were alive, low autofluorescent, lineage mix negative, HLA-DR ${ }^{+}$ cells, CD11 ${ }^{+}$cell, pDCs were CD11c ${ }^{-}$but $\mathrm{CD} 123^{+}$. Isolation of $\mathrm{mDC}$ from thawed BAL cells was performed using a FACS ARIA (BD Biosciences with Diva software and for analysis FlowJo software (Tree Star Inc.) was used. In a previous study, we showed that $\mathrm{mDCs}$ do not show an altered phenotype or altered $\mathrm{T}$ cell activating capacity after a freeze-thaw cycle [27].

\section{Immunohistochemistry of airway mucosa biopsies}

Immunohistochemistry was performed in a half automatic stainer (Sequenza) using primary monoclonal antibodies against human CD11c (SHCL-3; BD Biosciences) and
CD86 (2331(FUN-1); BD Biosciences). DCs were identified based on morphology and CD11c positivity in a haematoxylin background staining, as previously described [28]. Control staining was performed with an irrelevant mAb of the same subclass. All biopsy sections were stained in one session to reduce inter-staining variation and analysed in a blinded fashion by two different researchers. Sections from lung mucosal biopsies fulfilled the following criteria: intact epithelium, a subepithelial mucosa of $100 \mu \mathrm{m}$ depth and a good overall morphological quality.

\section{Functional testing of DCs in vitro}

Isolated BAL mDCs were mixed with allogeneic naïve $\mathrm{CD}^{+} \mathrm{T}$ cells isolated from a healthy donor as described previously [27] in a 1:20 ratio and cultured in RPMI 1640 medium at $37^{\circ} \mathrm{C}$ for 5 days. At day 5 , a portion of the cells was harvested for flow cytometry measurements and to the remaining cells $3 \mathrm{H}$-thymidine $(0.5 \mu \mathrm{Ci} /$ well, Packard $)$ was added and after 16 hours cell proliferation was determined by scintillation counting (Top count model B9912/ VI, Packard Bioscience Benelux). In order to culture moDCs, monocytes were isolated from PBMCs using CD14 beads (Miltenyi), according to the manufacturer's instructions. Monocytes were then resuspended at $1 \times 10^{6}$ cells/ $\mathrm{ml}$ in RPMI 1640 culture medium, supplemented with 10\% FCS, $50 \mu \mathrm{g} / \mathrm{ml}$ gentamycin (Gibco), $1000 \mathrm{U} / \mathrm{ml}$ GMCSF (Immuno Tools) and $200 \mathrm{U} / \mathrm{ml} \mathrm{IL-4} \mathrm{(R \& D)} \mathrm{and} \mathrm{cul-}$ tured at $37^{\circ} \mathrm{C}$ for 7 days [27]. Mo-DCs were co-cultured with allogeneic naïve $\mathrm{CD}^{+} \mathrm{T}$ cells for 5 days. T cell labeling with carboxyfluorescein succinimidyl ester (CFSE)-was performed using standard procedures.

Cytokine measurements in supernatants of DC-T cell co-cultures was performed using the human in a 25-plex Luminex assay cytokine and chemokine kit (Invitrogen, Carlsbad, CA) and run on a Luminex 100 System (Luminex Corporation, Austin, TX), according to the manufacturer's protocol. 


\section{Statistical analysis}

Results were compared using a two-tailed Mann Whitney $U$ test. Differences were considered significant at $\mathrm{P} \leq 0.05$.

\section{Results}

\section{BAL characteristics}

In this study we investigated BAL, peripheral blood and mucosal biopsies from newly diagnosed sarcoidosis patients and healthy controls (see: Mat \& Methods and Table 1 for patient characteristics). Sarcoidosis patients displayed increased BAL cellularity (median: $327 \times 10^{3}$ total cells $/ \mathrm{ml}$ ), compared to healthy controls (median: $118 \times 10^{3}$ total cells $/ \mathrm{ml}, \mathrm{p}=0.06$ ), in agreement with previous reports $[27,29,30]$. This increased cellularity in BAL was paralleled by increased proportions of lymphocytes and increased CD4/CD8 ratios (median: 4.8; range 1.222). BAL lymphocytes in sarcoidosis are reported to be highly positive for the Th1-specific chemokine receptor CXCR3 [31]. Accordingly, the closely related CXCR3 ligands CXCL9, also known as monokine induced by IFN $\gamma$ - (MIG) and CXCL10, also known as IFN $\gamma$-induced protein of $10 \mathrm{kDa}$ (IP-10), are elevated in BAL fluid [32]. When we measured the levels of these chemokines in BAL fluid in the same patients tested for $\mathrm{mDC}$ function, we found that they were elevated: for CXCL9 the median was $533 \mathrm{pg} / \mathrm{ml}$ (range 65-1397) in patients and $43 \mathrm{pg} / \mathrm{ml}$ (range 21-59; p = 0.0004) in healthy controls and for CXCL10 these values were $360 \mathrm{pg} / \mathrm{ml}$ (range 34-957) in patients and $0 \mathrm{pg} / \mathrm{ml}(0-96 ; \mathrm{p}<0.003)$ in controls.

\section{Increased $\mathrm{mDCs}$ in BAL and blood in sarcoidosis}

To investigate DCs in pulmonary sarcoidosis, we first analyzed the numbers of DC subsets in BAL and peripheral blood from patients $(\mathrm{mDC}(\mathrm{n}=16), \mathrm{pDC}(\mathrm{n}=8))$ and healthy controls $(n=6)$. The gating strategy used to identify mDCs and pDCs, shown in Figure 1, was previously published by us and others $[27,33]$. The proportions of HLA-DR ${ }^{+} \mathrm{CD} 11 \mathrm{c}^{+} \mathrm{mDC}$ in total BAL cells did not significantly differ between sarcoidosis patients and healthy controls (median: $0.26 \%$, range: $0.07-1.4$ and median: $0.17 \%$, range: $0.03-0.43$, respectively; Figure $2 \mathrm{~A}$ ), corroborating earlier studies [24]. However, the absolute numbers of $\mathrm{mDC}$ s were significantly elevated in patients (median 608 cells/ml, range: 217-3,965), when compared with healthy controls (median 123 cells/ml, range: 1011,941, $\mathrm{p}=0.05$ ).

In the BAL from sarcoidosis patients the populations of interleukin-3 receptor (IL-3R)/CD123-expressing HLA-DR ${ }^{+}$CD $11 \mathrm{c}^{-} \mathrm{pDCs}$ were increased, both in proportions (median $0.06 \%$, range $0.02-0.36$, compared with healthy controls: median $0.03 \%$, range $0.01-0.08, \mathrm{p}=$ 0.03 ) and in absolute numbers (median: 201 cells $/ \mathrm{ml}$, range: $23-1740$, compared with healthy controls: median 17 cells/ml, range 11-133, $\mathrm{p}=0.02$; Figure $2 \mathrm{~A}$ ).

In order to further validate these results, we additionally analyzed proportions of $\mathrm{mDCs}$ and $\mathrm{pDCs}$ in macrophage-depleted BAL from 15 patients and 9 controls. Median age of patients in this subgroup was 37 years (range: 23-69, 1 smoking) and controls 29 years (range: 21-50, 4 smoking). Controls consisted of 6 healthy controls and 3 individuals without pulmonary disease in whom there were a need to exclude sarcoidosis (see also Mat \& Methods). After macrophage depletion, proportions of $\mathrm{mDCs}$ and $\mathrm{pDCs}$ were generally higher, as was to be expected. The proportions of $\mathrm{mDCs}$ in macrophagedepleted BAL were significantly elevated in patients (median $1.61 \%$, range: $0.55-3.2$ ), when compared with healthy controls (median 1.01\%, range: 0.26-1.60, p = 0.025 ; Figure 2B). Proportions of pDCs in macrophagedepleted BAL tended to be higher in patients (median $0.16 \%$, range: $0.03-0.88$ ), when compared with healthy controls (median 0.11\%, range: 0.03-0.52), but were not significantly different (Figure 2B).

In a blood sample, concurrently drawn from the patients who's BAL findings are reported in Figure 2A, we observed an increase in mDCs in sarcoidosis patients, both in proportions (median: $0.24 \%$, range: $0.03-1.71$, compared with healthy controls $0.11 \%$, range $0.08-0.13$, $\mathrm{p}=0.01$ ) and in numbers (median: $1,441 / \mathrm{ml}$, range: 511 14,432, compared with healthy controls: median 933, range 638-1,102, $\mathrm{p}<0.01$; Figure $2 \mathrm{C}$ ). In contrast, no differences were observed in $\mathrm{pDC}$ numbers or proportions between patients and controls (Figure 2C). Peripheral blood from sarcoidosis patients and healthy controls also did not differ in the total numbers of PBMCs per ml (data not shown). Overall, we did not observe an association between numbers of $\mathrm{mDCs}$ or $\mathrm{pDCs}$ in BAL or blood and disease stage, as classified by Scadding [34] (data not shown).

Next, we set out to investigate whether the increase in DCs in BAL of sarcoidosis patients was associated with enhanced maturation of DCs in BAL and blood. In peripheral blood the expression of the CD80, CD86, CD40, CD83 and CD208 maturation markers on mDCs or pDCs was low and did not differ between sarcoidosis patients and healthy control subjects (data not shown). When analyzing CD40, CD80 (B7-1), CD83, CD86 (B72 ), and CD208/DC-LAMP expression on mDCs and PDs from BAL we found considerable heterogeneity in marker expression in repeat experiments, precluding conclusions on differences in BAL $\mathrm{mDC}$ maturation between sarcoidosis patients and controls

In summary, in recently diagnosed sarcoidosis patients we found an increase in mDCs and pDCs in the BAL and $\mathrm{mDCs}$ in peripheral blood, irrespective of disease stage. 


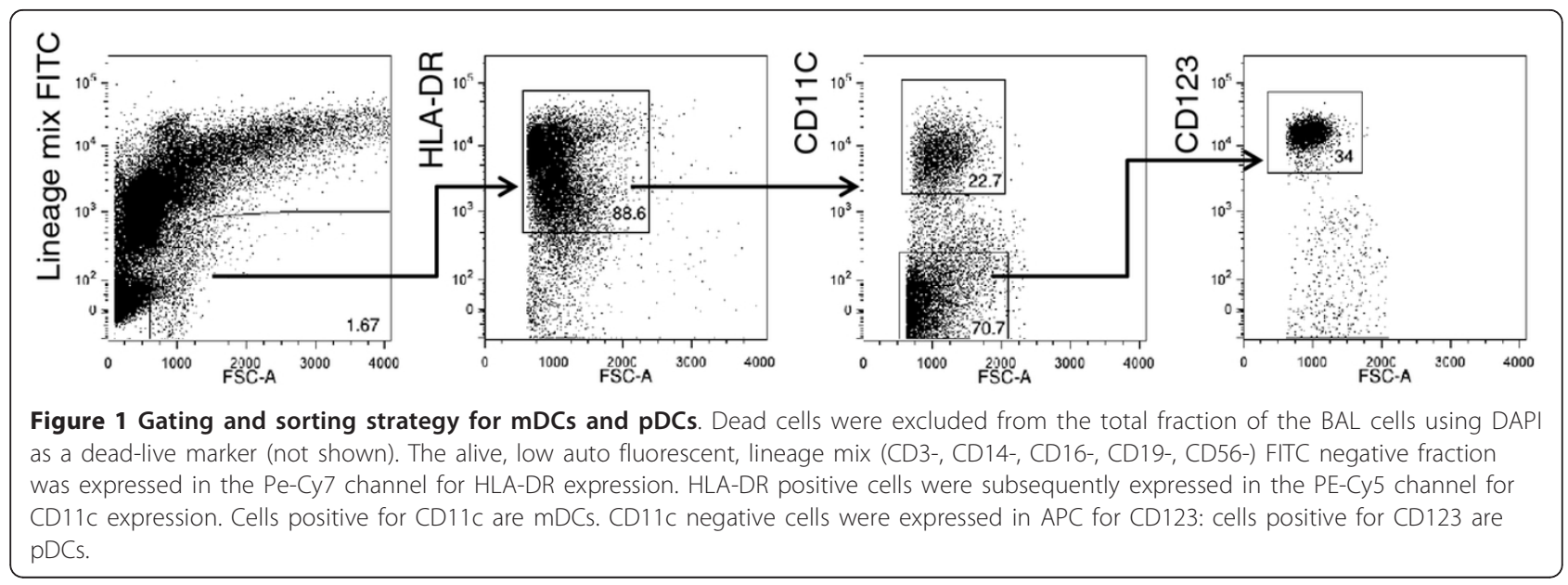

\section{BAL mDCs from sarcoidosis patients are immunocompetent}

Next, we evaluated whether an increase in mDCs in the BAL from sarcoidosis patients was associated with either enhanced or diminished $\mathrm{T}$ cell activation, the latter of which has been suggested for blood-derived DCs in sarcoidosis [25]. We applied our previously developed flow cytometric strategy for the isolation of $\mathrm{mDCs}$ from BAL to sort mDCs from BAL of 9 sarcoidosis patients (1 smoker, median age 29, range 23-64) and 6 healthy controls (no smokers, median age 22.5 , range $20-24$ ). In a previous study we showed that using a newly developed technique $\mathrm{mDC}$ can be isolated from BAL using flow cytometric sorting with a high degree of purity (approximately 94\%, range 91,6-96,6) [27]. To test the capacity of these sorted $\mathrm{mDCs}$ to induce $\mathrm{T}$ cell proliferation and differentiation, we performed co-culture experiments with allogenic naïve $\mathrm{CD}^{+} \mathrm{T}$ cells. Upon 5 days of coculture, naïve $\mathrm{CD} 4^{+} \mathrm{T}$ cells displayed clear proliferation, when compared with unstimulated $\mathrm{CD}^{+} \mathrm{T}$ cells. No differences were found between co-cultures with BAL mDCs sorted from healthy controls or from sarcoidosis patients (as measured by $3 \mathrm{H}$-thymidine incorporation; Figure $3 \mathrm{~A})$. In these co-culture experiments naïve $\mathrm{CD} 4^{+}$ $\mathrm{T}$ cells differentiated into $\mathrm{CD} 25^{+} \mathrm{CD} 127^{\text {low }}$ Foxp $3^{+}$regulatory $\mathrm{T}$ cells, $\mathrm{CD} 45 \mathrm{RO}^{+}$memory $\mathrm{T}$ cells, $\mathrm{CXCR}^{+} \mathrm{Th} 1$ or $\mathrm{CCR}^{+}{ }^{+} \mathrm{Th} 2$ cells, whereby we did not observe significant differences between co-cultures with mDCs from sarcoidosis patients and with $\mathrm{mDCs}$ from healthy controls (Figure 3B). Likewise, we found similar levels of cytokines, including TNF $\alpha$, IFN $\gamma$, IL-4, IL-5, IL-13 and IL-17 (Figure 3C).

Taken together, these findings indicate that mDCs from the BAL from sarcoidosis patients were functional and did not display diminished immunoreactivity, when compared with mDCs from healthy controls.

\section{Monocyte-derived DCs from sarcoidosis patients induce increased TNF $\alpha$ expression}

To investigate whether intrinsic DC defects in sarcoidosis might lead to aberrant $\mathrm{T}$ cell responses independent of the lung microenvironment, we cultured monocyte-derived DCs (mo-DCs) from 10 sarcoidosis patients and 10 healthy controls. Expression of CD80, CD86, CD40 and CD83 was comparable in the two groups (Figure 4A). When mo-DC function was tested in co-cultures with allogeneic naïve $C D 4^{+} \mathrm{T}$ cells, mo-DCs from sarcoidosis patients and healthy controls did not manifest differences in their capacity to induce $\mathrm{T}$ cell proliferation (Figure 4B), $\mathrm{T}$ cell activation as assessed by membrane expression of the IL-2R/CD25 (Figure 4C), or regulatory T cell differentiation (Figure 4D). When cytokine production was measured by Luminex bead assays, we observed increased TNF $\alpha$ expression in co-cultures of mo-DCs from sarcoidosis patients, when compared with co-cultures of mo-DC from healthy controls (Figure 4E). Other cytokines tested, including IFN $\gamma$, IL-17, IL-4, IL-5 and IL-13 were not different between the two groups of cultures.

Taken together, these data show that DCs from sarcoidosis patients examined outside of the disease microenvironment were not intrinsically more mature, but do show an increased propensity to induce the production of TNF $\alpha$, a cytokine pivotal in sarcoidosis pathogenesis.

\section{Increased numbers of mature $\mathrm{CD}^{+} \sigma^{+} \mathrm{DCs}$ surrounding granulomas}

Finally, we determined the numbers, location and activation status of DCs in the airways in mucosal airway biopsies from 26 sarcoidosis patients and 20 healthy controls. Identification of DCs in biopsy material can be hampered by the absence of one marker unique for DCs; CD11c can be expressed on monocytes, macrophages and neutrophils as well. However, in combination with morphological 


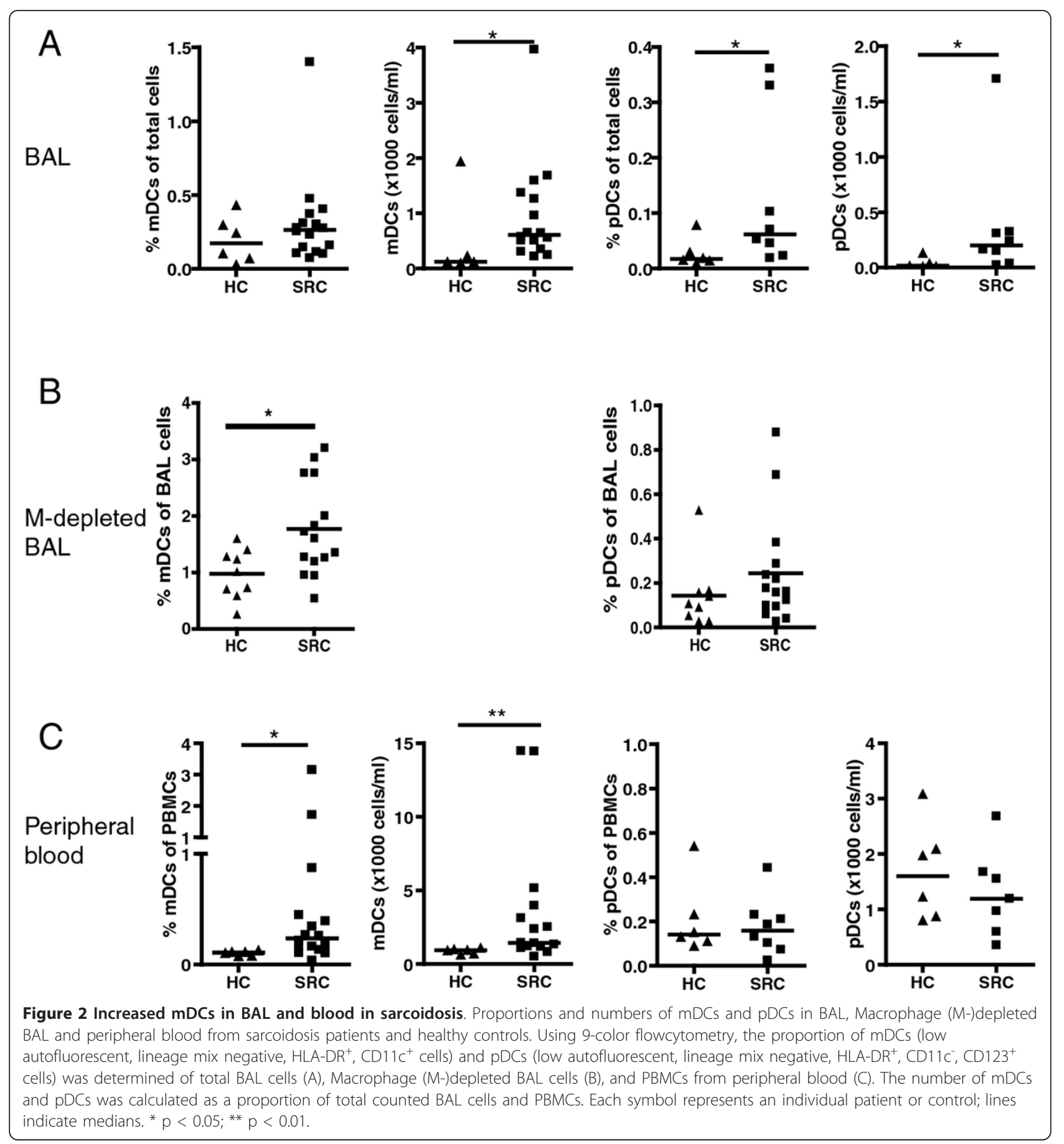

features tissue DCs can be identified with confidence in histological sections, as we have previously shown [28]. Cells positive for CD11c showing a characteristic DC morphology were found in the subepithelial layer of the airways in healthy subjects, as reported previously [35] (Figure 5A). Ten out of 26 mucosal biopsies from sarcoidosis patients contained clear granulomas, and in those CD $11 \mathrm{c}^{+}$DCs were seen predominantly surrounding the granulomas, confirming earlier studies [21] (Figure 5B). We also observed weak CD11c expression in the center of granulomas, perhaps reflecting CD11c expression on myeloid derived epithelioid histiocytes or interdigitating dendrites. Granuloma-containing biopsies displayed significantly increased CD11c ${ }^{+}$cell numbers, when compared with either healthy controls $(\mathrm{p}=0.0011$ ) or nongranulomatous biopsies $(\mathrm{p}=0.0014)$ (Figure $5 \mathrm{C}$ ). 

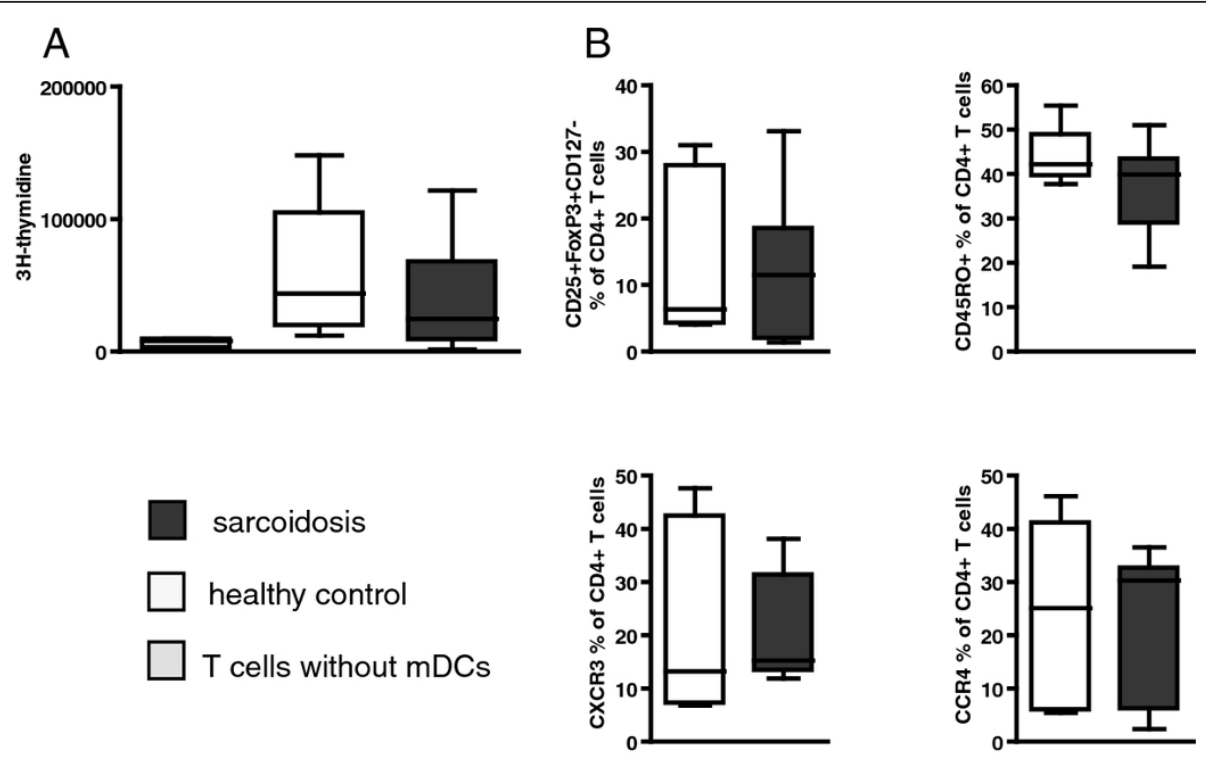

C
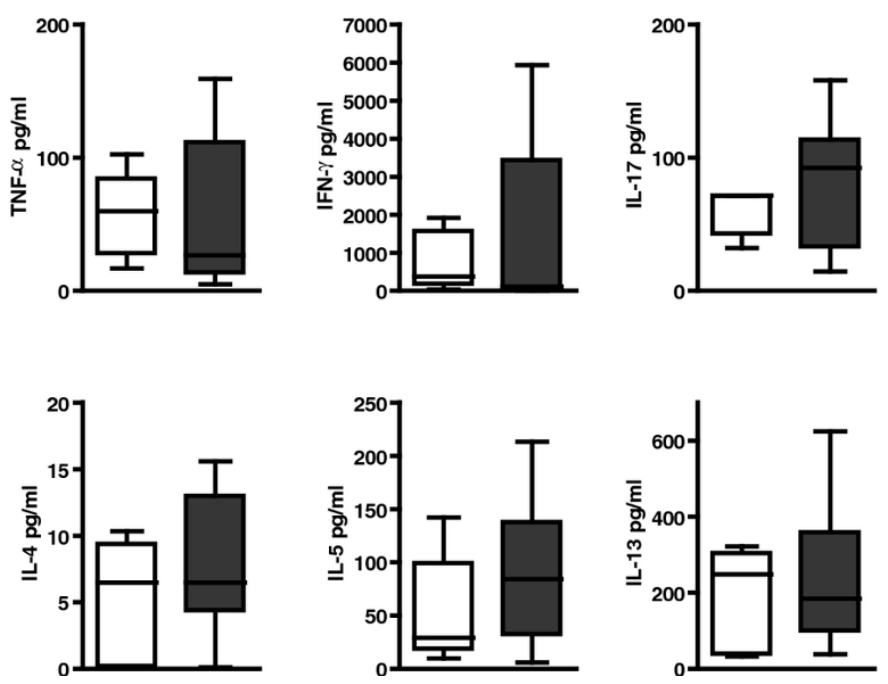

Figure 3 BAL mDCs from sarcoidosis patients are immunocompetent in co-cultures with $\mathrm{T}$ cells. Induction of $\mathrm{T}$ cell proliferation and differentiation by $\mathrm{mDC}$ s isolated from BAL from sarcoidosis patients. mDCs (defined as low autofluorescent, lineage mix negative, HLA-DR ${ }^{+}$, CD11 $\mathrm{c}^{+}$cells), isolated from BAL from sarcoidosis patients and healthy controls, were tested in a MLR with naïve allogeneic CD4 ${ }^{+} \mathrm{T}$ cells. (A) After 5 days of co-culture, $T$ cell proliferation was measured using $3 \mathrm{H}$-thymidine incorporation. (B) $\mathrm{T}$ cell differentiation was assessed using markers for Tregs $\left(C D 25+\right.$ Foxp3 $^{+}$CD127 low, memory T cells $\left(C D 45 \mathrm{RO}^{+}\right)$, Th1 $\left(\mathrm{CXCR}^{+}\right)$and Th2 $\left(\mathrm{CCR} 4^{+}\right)$cells. (C) Cytokines were measured in the supernatant of the co-culture using a bead-based cytokine kit. Data are presented as boxplots, whiskers indicate minimum and maximum of the data.

To assess the maturation state of the mucosal DCs, double stainings were performed for CD11c and CD86. In granuloma-containing biopsies, the proportions of CD $11 \mathrm{c}^{+}$cells co-expressing CD86 was significantly increased (median 88\%, range 77-96\%), when compared with healthy controls (median 50\%, range 4-95) $(\mathrm{p}=$ 0.0012 ), but not significantly different from values in non-granulomatous biopsies from patients (median $82 \%$, range $0-100 \%$ ). The proportion of $\mathrm{CD}^{+} 6^{+} \mathrm{DCs}$ tended to be higher in non-granulomatous biopsies, compared with healthy controls, but differences did not reach significance, probably related to the variation of $\mathrm{CD} 86^{+}$ expression in healthy individuals.

Taken together, these results show that granuloma formation was associated with an increase in number and maturation status of DCs, providing evidence for the involvement of DCs in granuloma formation or maintenance in sarcoidosis. 


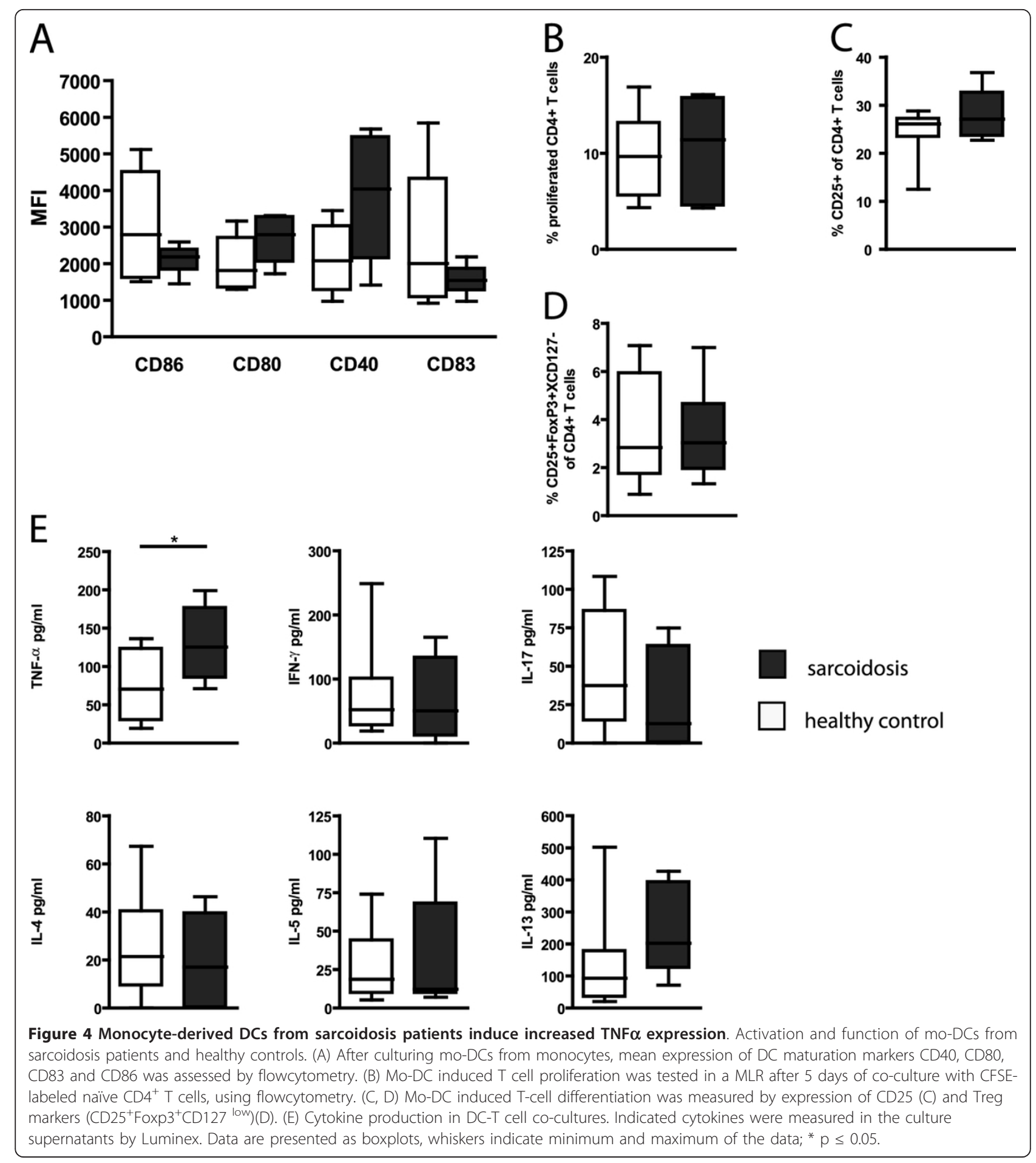

\section{Discussion}

DCs are pivotal antigen presenting cells and the prime suspects for initiating granuloma formation and $\mathrm{T}$ cell alveolitis characteristic for pulmonary sarcoidosis. Paradoxically, local DCs have been suggested to be phenotypically and functionally immature [25]. In contrast, we provide in this report the involvement of mature, functional DCs in pulmonary sarcoidosis. First, pulmonary sarcoidosis patients have increased numbers of $\mathrm{mDCs}$ in BAL, granuloma containing mucosal biopsies and blood. Second, mDCs in granuloma-containing biopsies show increased expression of a maturation marker. Third, 


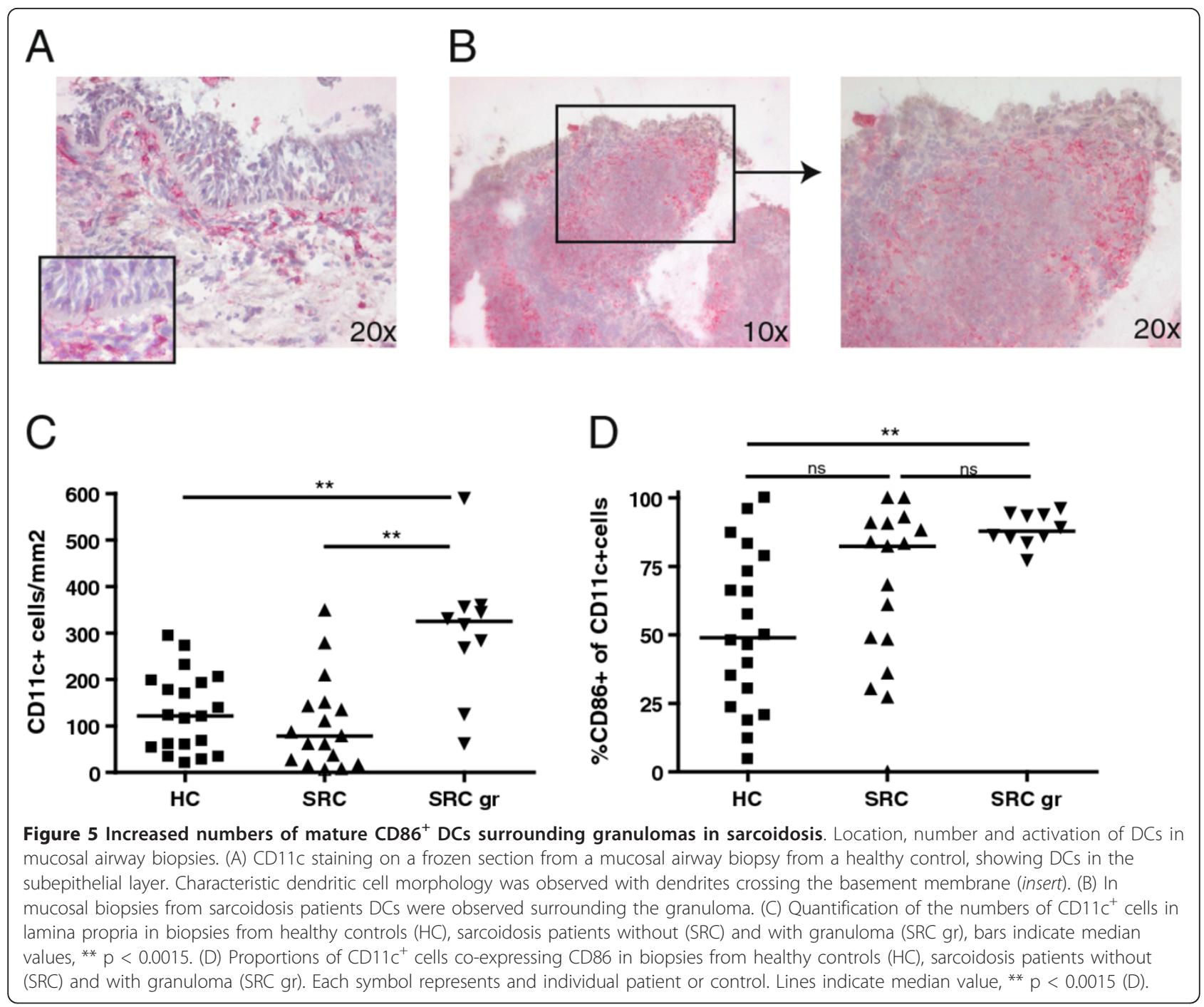

mDCs from BAL are very well capable of inducing $\mathrm{T}$ cell proliferation and differentiation and show no signs of anergy. Finally, mo-DCs from sarcoidosis patients induce more TNF $\alpha$ in co-cultures with allogeneic $\mathrm{CD} 4^{+} \mathrm{T}$ cells, compared to mo-DCs from healthy controls. Taken together these results indicate that pulmonary sarcoidosis is associated with increased numbers of mature, functionally competent DCs that intrinsically induce increased levels of a central mediator in sarcoidosis, TNFa.

Previous studies and ours report different results in numbers of mDCs in blood or BAL from sarcoidosis patients $[21,23,24]$. These differences may reflect variations in obtaining (e.g. volume of total BAL fluid), isolating (enriched cell populations vs. flow cytometric sorting), calculating (number per $\mathrm{ml}$ vs. proportions) and markers used for defining DC subsets. E.g we found increased proportions and numbers of $\mathrm{mDCs}$ in blood from sarcoidosis patients compared to healthy controls by calculating $\mathrm{mDCs}$ as the proportion of PBMCs from the same sample, while others reported (similar) numbers of mDCs as a proportion of total leucocytes, obtained by lysis of red blood cells, and calculated from a concurrent drawn blood sample [23], or even decreased numbers of $\mathrm{mDCs}$ calculated by using proportions of a DC-enriched cell population [21]. We performed BAL with $200 \mathrm{ml}$ saline, compared to e.g. $100 \mathrm{ml}$ in other reports [24]. It is conceivable that an increase in BAL fluid amount reduces the relative contribution of the larger conducting airways to the retrieved amount of fluid, thus increasing the cellular yield from the alveolar compartment, increasing the yield of DCs.

To the best of our knowledge we report for the first time functional tests on mDCs from the site of disease in pulmonary sarcoidosis. DCs isolated from BAL from sarcoidosis patients did not induce enhanced $\mathrm{T}$ cell 
proliferation, a skewed $\mathrm{T}$ cell differentiation or significant differences in the induction of several cytokines in a MLR with allogeneic naïve CD4+ $\mathrm{T}$ cells, compared to controls. Several explanations related to the microenvironment of the lung where $\mathrm{DC}-\mathrm{T}$ cell interactions take place, are possible: First, DCs from BAL from sarcoidosis patients may have already interacted with $\mathrm{T}$ cells, and are beyond their functional maximum upon isolation from BAL. This is supported by studies showing that after initial exposure to a stimulus, DCs produce IL-12, important for inducing $\mathrm{T}$ cell proliferation, for a limited period of 10-18 hours [36]. Second, it is perhaps the sheer number of DCs and not the maturation status that determines the in vivo outcome of $\mathrm{T}$ cell proliferation in sarcoidosis. Although the number of DCs in BAL is in general very low, DCs in the BAL are thought to reflect only a small percentage of pulmonary DCs [37]. We found increased numbers of mDCs per $\mathrm{ml}$ of BAL in sarcoidosis patients, perhaps indicating increased numbers of interstitial DCs that may travel to the draining lymph node for antigen presentation. Future investigations in the lymph node compartment may shed light on this issue. Third, perhaps an intrinsic $\mathrm{T}$ cell factor is (additionally) required to induce the exaggerated $\mathrm{T}$ cell response observed in sarcoidosis. Interestingly, a single nucleotide polymorphism (SNP) in the IL-23 receptor was recently associated with sarcoidosis [38]. IL-23 is a cytokine that is essential for the induction of IL-17 producing CD4 ${ }^{+} \mathrm{T}$ cells (Th17 cells) that were recently associated with granuloma formation in sarcoidosis by us and others [38,39]. Interestingly, we did observe a modest but not significant increase in IL17 production in the MLR supernatant of sarcoidosis patients. Finally, influx of $\mathrm{CD}_{4}^{+} \mathrm{T}$ cells into the bronchoalveolar space may primarily be determined by chemotactic factors. Our data on enhanced levels of MIG and IP10 in BAL, well-known chemotactic factors for Th1 cells, support this notion and confirm earlier reports $[32,40]$.

TNF $\alpha$ is a pivotal mediator of granuloma formation and maintenance, and is thought to play an important role in sarcoidosis pathogenesis [41]. Indeed, enhanced TNF $\alpha$ secretion by BAL macro-phages is observed in sarcoidosis [3]. In addition, TNF $\alpha$ is also expressed by Th1 and Th17 cells and both T helper cell subsets are likely involved in sarcoidosis pathogenesis [38]. Polymorphisms in the $T N F \alpha$ locus were associated with sarcoidosis phenotype and prognosis and have been linked to altered TNF $\alpha$ expression $[42,43]$. Importantly, TNF $\alpha$ is an essential target for treatment [44] and we found that mo-DCs from patients with sarcoidosis, not influenced by the micro-environment of the lung, induced increased TNF $\alpha$ release upon interaction with naïve $\mathrm{CD} 4^{+} \mathrm{T}$ cells when compared to controls. Our results indicate that DCs are intrinsically different in sarcoidosis patients. Nevertheless, we found that mo-DCs from sarcoidosis patients were equally capable of inducing proliferation and differentiation in allogeneic naïve $\mathrm{T}$ cells, compared to healthy controls. In the current study we did not explore whether mo-DCs from sarcoidosis patients lead to skewing of $\mathrm{T}$ cell differentiation towards a Th1/Th17 phenotype compared to controls, and this remains to be investigated. In co-cultures with PBMCs, mo-DCs were previously reported to demonstrate a reduced capacity to induce $\mathrm{T}$ cell proliferation (26). However, it is conceivable that other cells in the PBMC fraction, e.g. regulatory $\mathrm{T}$ cells (Tregs), influenced $\mathrm{T}$ cell proliferation. Indeed, we found increase numbers of Tregs in the PBMC fraction from sarcoidosis patients' blood (unpublished observations).

Granulomas are thought to arise upon failure of the immune system to clear invading pathogens. Earlier reports on diminished DC maturation and immune reactivity led to the notion that DC anergy may contribute to granuloma formation in sarcoidosis, e.g. due to diminished antigen presenting capabilities or ineffective induction of a T helper cell response [25]. However, we found that both mDCs in BAL and in granuloma-containing airway biopsies were increased in number and had enhanced expression of maturation marker CD86 in the vicinity of granulomas. Furthermore, mDCs isolated from BAL displayed normal immune reactivity compared to healthy controls. Intriguingly, also in non-granulomatous mucosal airway biopsies from sarcoidosis patients there was a tendency towards increased numbers and maturation of mDCs, compared to healthy controls, although this was not statistically significant. It is tempting to speculate that these mucosal DCs are activated upon acquiring antigen from the airway lumen and subsequently present the antigen in a draining lymph node or are involved in mucosal granuloma formation. Taken together our results strongly support the notion that $\mathrm{mDCs}$ are involved in granuloma formation and maintenance in sarcoidosis, rather than the alternative that DCs are defective in supporting the adaptive immune system in antigen clearance. Our study included patients with newly diagnosed stage I/II sarcoidosis, we did not include patients with stage III/IV disease, and our results are therefore limited to patients presenting with early disease. We did not find a correlation between stage I or II and number of mDCs or pDCs. However, chest X-ray stage often poorly correlates with disease activity or progression. Thus, the role of DCs in granuloma formation or maintenance in subjects with advanced disease remains to be determined.

In conclusion, we provide evidence for the involvement of DCs in antigen presentation and granuloma formation at the site of disease in pulmonary sarcoidosis patients. Intrinsic genetic alterations in key APCs may underlie 
the exaggerated immune response to a hard to discern antigen that is characteristic of sarcoidosis. Immunological measurements and functional examination of DC and $\mathrm{T}$ cell subsets from large groups of carefully genotyped patients should prove very interesting.

\section{Acknowledgements}

$\mathrm{BtB}$ is supported by an unrestricted grant of Astra Zeneca, The Netherlands. The authors gratefully acknowledge the participations in this study of patients and treating physicians from ErasmusMC University Medical Hospital, Sint Franciscus Gasthuis, Maasstad hospital, Rotterdam, The Netherlands, Amphia Ziekenhuis, Breda, The Netherlands, and Zorggroep Twente, the Netherlands. Marthe Paats, MD is gratefully acknowledged for expert support in BAL analysis.

\section{Author details}

${ }^{1}$ Department of Pulmonary Medicine, Erasmus MC, Dr. Molewaterplein 50, 3015, GE Rotterdam, The Netherlands. ²Department of Respiratory Diseases, Laboratory of Mucosal Immunology, MRBI, University Hospital Gent, De Pintelaan 185, B9000 Ghent, Belgium.

\section{Authors' contributions}

$\mathrm{BL}, \mathrm{HCH}, \mathrm{BB}$ and $\mathrm{BtB}$ designed the study design and the experiments. $\mathrm{Bt} \mathrm{B}$, $A K, F M$ and $H H$ were responsible for flow cytometry and data collection. BtB, $B B, B L$, and $\mathrm{RH}$ analyzed the data. $\mathrm{Bt} B, \mathrm{BB}$ and $\mathrm{RH}$ drafted the manuscript. $\mathrm{BtB}, \mathrm{AK}, \mathrm{FM}, \mathrm{HH}, \mathrm{HCH}, \mathrm{RH}, \mathrm{BL}$ and $\mathrm{BB}$ read, critically revised and approved the final manuscript. All authors read and approved the final manuscript.

\section{Competing interests}

The authors declare that they have no competing interests.

Received: 9 July 2011 Accepted: 18 April 2012 Published: 18 April 2012

\section{References}

1. Baughman RP, Teirstein AS, Judson MA, Rossman MD, Yeager $H$ Jr, Bresnitz EA, DePalo L, Hunninghake G, lannuzzi MC, Johns CJ, et al: Clinical characteristics of patients in a case control study of sarcoidosis. Am J Respir Crit Care Med 2001, 164(10 Pt 1):1885-1889.

2. Statement on sarcoidosis. Joint Statement of the American Thoracic Society (ATS), the European Respiratory Society (ERS) and the World Association of Sarcoidosis and Other Granulomatous Disorders (WASOG) adopted by the ATS Board of Directors and by the ERS Executive Committee, February 1999. Am J Respir Crit Care Med 1999, 160(2):736-755.

3. Iannuzzi MC, Rybicki BA, Teirstein AS: Sarcoidosis. N Engl J Med 2007, 357(21):2153-2165

4. Baughman RP, Culver DA, Judson MA: A Concise Review of Pulmonary Sarcoidosis. Am J Respir Critical Care Med 2011, 183(5):573-581.

5. Rybicki BA, lannuzzi MC, Frederick MM, Thompson BW, Rossman MD, Bresnitz EA, Terrin ML, Moller DR, Barnard J, Baughman RP, et al: Familial aggregation of sarcoidosis. A case-control etiologic study of sarcoidosis (ACCESS). Am J Respir Crit Care Med 2001, 164(11):2085-2091.

6. Moller DR: Potential etiologic agents in sarcoidosis. Proc Am Thorac Soc 2007, 4(5):465-468.

7. Oswald-Richter KA, Drake WP: The etiologic role of infectious antigens in sarcoidosis pathogenesis. Semin Respir Crit Care Med 2010, 31(4):375-379.

8. Zissel G, Ernst M, Schlaak M, Muller-Quernheim J: Accessory function of alveolar macrophages from patients with sarcoidosis and other granulomatous and nongranulomatous lung diseases. J Investig Med 1997, 45(2):75-86.

9. Agostini C, Trentin L, Perin A, Facco M, Siviero M, Piazza F, Basso U, Adami F, Zambello R, Semenzato G: Regulation of alveolar macrophage-T cell interactions during Th1-type sarcoid inflammatory process. Am J Physiol 1999, 277(2 Pt 1):L240-L250.

10. Prasse A, Georges CG, Biller H, Hamm H, Matthys H, Luttmann W, Virchow JC Jr: Th1 cytokine pattern in sarcoidosis is expressed by bronchoalveolar CD4+ and CD8+ T cells. Clin Exp Immunol 2000, 122(2):241-248.
11. Inui $\mathrm{N}$, Chida $\mathrm{K}$, Suda T, Nakamura $\mathrm{H}$ : TH1/TH2 and TC1/TC2 profiles in peripheral blood and bronchoalveolar lavage fluid cells in pulmonary sarcoidosis. J Allergy Clin Immunol 2001, 107(2):337-344.

12. Wahlstrom J, Katchar K, Wigzell H, Olerup O, Eklund A, Grunewald J: Analysis of intracellular cytokines in CD4+ and CD8+ lung and blood T cells in sarcoidosis. A J Respir Crit Care Med 2001, 163(1):115-121.

13. Nicod LP, Isler P: Alveolar macrophages in sarcoidosis coexpress high levels of CD86 (B7.2), CD40, and CD30L. Am J Respir Cell Mol Biol 1997, 17(1):91-96

14. Zaba LC, Smith GP, Sanchez M, Prystowsky SD: Dendritic Cells in the Pathogenesis of Sarcoidosis. Am J Respir Cell Mol Biol 2010, 42(1):32-39.

15. GeurtsvanKessel $\mathrm{CH}$, Lambrecht BN: Division of labor between dendritic cell subsets of the lung. Mucosal Immunol 2008, 1(6):442-450.

16. Ito T, Schaller M, Hogaboam CM, Standiford TJ, Sandor M, Lukacs NW Chensue SW, Kunkel SL: TLR9 regulates the mycobacteria-elicited pulmonary granulomatous immune response in mice through DCderived Notch ligand delta-like 4. J Clin Invest 2009, 119(1):33-46.

17. Iyonaga K, McCarthy KM, Schneeberger EE: Dendritic cells and the regulation of a granulomatous immune response in the lung. Am J Respir Cell Molecul Biol 2002, 26(6):671-679.

18. Tsuchiya T, Chida K, Suda T, Schneeberger EE, Nakamura H: Dendritic cell involvement in pulmonary granuloma formation elicited by bacillus calmette-guerin in rats. Am J Respir Crit Care Med 2002, 165(12):1640-1646.

19. Willart MA, Jan-de-Heer H, Hammad H, Soullie T, Deswarte $K$, Clausen BE, Boon L, Hoogsteden HC, Lambrecht BN: The lung vascular filter as a site of immune induction for $\mathrm{T}$ cell responses to large embolic antigen. J Exp Med 2009, 206(12):2823-2835.

20. Munro CS, Campbell DA, Du Bois RM, Mitchell DN, Cole PJ, Poulter LW: Dendritic cells in cutaneous, lymph node and pulmonary lesions of sarcoidosis. Scand J Immunol 1987, 25(5):461-467.

21. Ota M, Amakawa R, Uehira K, Ito T, Yagi Y, Oshiro A, Date Y, Oyaizu H, Shigeki T, Ozaki $Y$, et al: Involvement of dendritic cells in sarcoidosis. Thorax 2004, 59(5):408-413

22. Tateyama M, Fujihara K, Itoyama Y: Dendritic cells in muscle lesions of sarcoidosis. Human pathology 2011, 42(3):340-346.

23. Mathew S, Bauer KL, Fischoeder A, Bhardwaj N, Oliver SJ: The anergic state in sarcoidosis is associated with diminished dendritic cell function. $J$ Immunol 2008, 181(1):746-755.

24. Lommatzsch M, Bratke K, Bier A, Julius P, Kuepper M, Luttmann W, Virchow JC: Airway dendritic cell phenotypes in inflammatory diseases of the human lung. Eur Respir J 2007, 30(5):878-886.

25. Zaba LC, Smith GP, Sanchez M, Prystowsky SD: Dendritic cells in the pathogenesis of sarcoidosis. Am J Respir Cell Molecul Biol 2010, 42(1):32-39.

26. Kulakova N, Urban B, McMichael AJ, Ho LP: Functional analysis of dendritic cell-T cell interaction in sarcoidosis. Clin Exp Immunol 2009, 159(1):82-86.

27. Ten Berge B, Muskens F, Kleinjan A, Hammad H, Hoogsteden HC, Lambrecht BN, Van den Blink B: A novel method for isolating dendritic cells from human bronchoalveolar lavage fluid. J Immunol Methods 2009, 351(1-2):13-23

28. KleinJan A, Willart M, van Rijt LS, Braunstahl GJ, Leman K, Jung S, Hoogsteden HC, Lambrecht BN: An essential role for dendritic cells in human and experimental allergic rhinitis. J Allergy Clin Immunol 2006, 118(5):1117-1125.

29. Rossi GA, Sacco O, Cosulich E, Damiani G, Corte G, Bargellesi A, Ravazzoni C: Pulmonary sarcoidosis: excess of helper $T$ lymphocytes and $T$ cell subset imbalance at sites of disease activity. Thorax 1984, 39(2):143-149.

30. Hunninghake GW, Crystal RG: Pulmonary sarcoidosis: a disorder mediated by excess helper T-lymphocyte activity at sites of disease activity. NeW Eng J Med 1981, 305(8):429-434.

31. Katchar K, Eklund A, Grunewald J: Expression of Th1 markers by lung accumulated T cells in pulmonary sarcoidosis. J Intern Med 2003, 254(6):564-571.

32. Nishioka Y, Manabe K, Kishi J, Wang W, Inayama M, Azuma M, Sone S: CXCL9 and 11 in patients with pulmonary sarcoidosis: a role of alveolar macrophages. Clin Exp Immunol 2007, 149(2):317-326.

33. Masten BJ, Olson GK, Tarleton CA, Rund C, Schuyler M, Mehran R, Archibeque T, Lipscomb MF: Characterization of myeloid and plasmacytoid dendritic cells in human lung. J Immunol 2006, 177(11):7784-7793. 
34. Scadding JG: Prognosis of intrathoracic sarcoidosis in England. A review of 136 cases after five years' observation. Brit Med J 1961, 2(5261):1165-1172.

35. Vermaelen K, Pauwels R: Pulmonary dendritic cells. Am J Respir Crit Care Med 2005, 172(5):530-551.

36. Langenkamp A, Messi M, Lanzavecchia A, Sallusto F: Kinetics of dendritic cell activation: impact on priming of $\mathrm{TH} 1, \mathrm{TH} 2$ and nonpolarized $\mathrm{T}$ cells. Nat Immunol 2000, 1(4):311-316.

37. Holt PG, Oliver J, Bilyk N, McMenamin C, McMenamin PG, Kraal G, Thepen T: Downregulation of the antigen presenting cell function(s) of pulmonary dendritic cells in vivo by resident alveolar macrophages. J Exp Med 1993, 177(2):397-407.

38. Facco M, Cabrelle A, Teramo A, Olivieri V, Gnoato M, Teolato S, Ave E, Gattazzo C, Fadini GP, Calabrese F, et al: Sarcoidosis is a Th1/Th17 multisystem disorder. Thorax 2011, 66(2):144-150.

39. Ten Berge B, Paats MS, Bergen IM, van den Blink B, Hoogsteden HC, Lambrecht BN, Hendriks RW, Kleinjan A: Increased IL-17A expression in granulomas and in circulating memory $T$ cells in sarcoidosis. Rheumatology (Oxford) 2012, 51(1):37-46.

40. Sugiyama K, Mukae H, Ishii H, Kakugawa T, Ishimoto H, Nakayama S, Shirai R, Fujii T, Mizuta Y, Kohno S: Elevated levels of interferon gammainducible protein-10 and epithelial neutrophil-activating peptide-78 in patients with pulmonary sarcoidosis. Respirology 2006, 11(6):708-714.

41. Wallis $R$, Ehlers $S$ : Tumor necrosis factor and granuloma biology: explaining the differential infection risk of etanercept and infliximab. Sem Arthritis Rheum 2005, 34(5):34-38.

42. Medica I, Kastrin A, Maver A, Peterlin B: Role of genetic polymorphisms in ACE and TNF-alpha gene in sarcoidosis: a meta-analysis. $J$ Hum Genet 2007, 52(10):836-847.

43. Wijnen PA, Nelemans PJ, Verschakelen JA, Bekers O, Voorter CE, Drent M: The role of tumor necrosis factor alpha G-308A polymorphisms in the course of pulmonary sarcoidosis. Tissue Antigens 2010, 75(3):262-268.

44. Baughman RP, Lower EE, Drent M: Inhibitors of tumor necrosis factor (TNF) in sarcoidosis: who, what, and how to use them. Sarcoidosis Vasc Diffuse Lung Dis 2008, 25(2):76-89.

doi:10.1186/1465-9921-13-33

Cite this article as: Berge et al.: Evidence for local dendritic cell activation in pulmonary sarcoidosis. Respiratory Research 2012 13:33.

\section{Submit your next manuscript to BioMed Central and take full advantage of:}

- Convenient online submission

- Thorough peer review

- No space constraints or color figure charges

- Immediate publication on acceptance

- Inclusion in PubMed, CAS, Scopus and Google Scholar

- Research which is freely available for redistribution

Submit your manuscript at www.biomedcentral.com/submit
Biomed Central 